\title{
Comparative study on bearing mechanism and design parameters of confined concrete arch joints in deep soft rock roadway
}

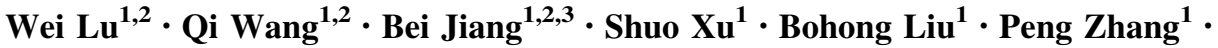 \\ Zhenhua Jiang ${ }^{1}$
}

Received: 13 July 2019/Revised: 21 August 2019/Accepted: 4 September 2019/Published online: 12 November 2019

(C) The Author(s) 2019

\begin{abstract}
Square confined concrete arch is increasingly used in deep soft rock roadway support because of its advantages of high strength and construction convenience. However, the design of confined concrete arch in underground engineering still remains in experience-based method and lacks quantitative analysis. As a connecting component between arch sections, the connection joints have an important influence on the internal force distribution and failure mechanism of support arch. Therefore, a reasonable design of arch joints is the premise of rational support design. Taking Liangjia Coal Mine, a typical deep soft rock mine in China, as research background, this paper fully compared the most widely used joint types of confined concrete arch as analytical objects: flange joints and casing joints. The main failure modes of these two kinds of joints under bending moment are defined. Laboratory and numerical tests are carried out to study the mechanical characteristics of joints. Based on the $M-\theta$ curve, the influence law of different design parameters is analyzed, and the design principles of joints are proposed. The research results could provide a theoretical basis for the design and application of confined concrete arch in related projects.
\end{abstract}

Keywords Confined concrete arch $\cdot$ Soft rock roadway $\cdot$ Bearing mechanism $\cdot$ Failure mode $\cdot$ Casing joint

\section{Introduction}

Under the background of rapid development of global underground engineering construction, the scale of underground engineering in mining, transportation and other fields continues to increase. More and more roadways or tunnels are constructed in complex geological conditions such as high crustal stress or extremely soft surrounding rock and therefore the construction of underground

Qi Wang

chinawangqi@163.com

1 Research Center of Geotechnical and Structural Engineering, Shandong University, Jinan 250061, China

2 Key Laboratory for Geo-mechanics and Deep Underground Engineering, China University of Mining and Technology, Beijing, China

3 School of Civil Engineering and Architecture, University of Jinan, Jinan 250022, China engineering is difficult. As the coal mine excavation entering the deep underground, the traditional support systems are insufficient in strength and inconvenient in construction (He et al. 2002). Conventional bolt-meshshotcrete support combined with section steel arch is difficult to meet the requirements of safety and stability in deep soft rock roadway.

In view of the supporting problems, new support system and technologies are constantly being studied, among which the confined concrete arch is a successful breakthrough (Wang et al. 2016, 2017). In the past 10 years, the confined concrete arch system has been widely used in many coal mines, such as Qian jia-ying Coal Mine, He gang-nan Coal Mine, Huafeng Coal Mine and Zhaolou Coal Mine, and has achieved remarkable results and extensive development (Li 2012; Meng 2013; Gao et al. 2015). A lot of achievements have been accumulated in field practice, laboratory test, numerical simulation, theoretical calculation and so on (Fig. 1). 

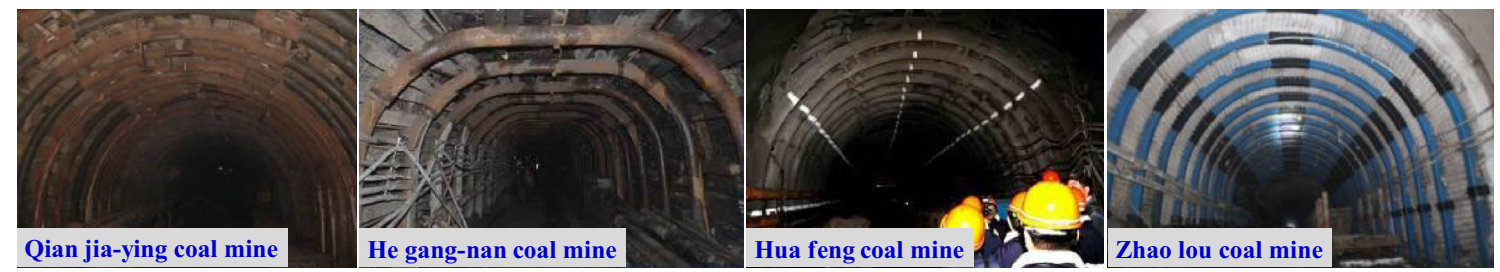

Fig. 1 Typical application cases of confined concrete arch

Confined concrete is a kind of structure in which concrete is filled into steel tube. Steel tube provides restraint to internal concrete, and meanwhile its compressive performance in enhanced. Confined concrete arch shows the advantages of high flexural rigidity and high ultimate strength, so it shows high resistance under the pressure of rock deformation.

In the coal mine support, the confined concrete arch is divided into several arch sections connected by joints. Different joint types have different stiffness and bearing capacity, which directly affect the distribution of internal force and the integral resistance of arch. There are many types of joints connecting confined concrete components while the joint types of the above-ground arch structure (such as bridge arch) and the underground arch structure. The application of different joint types has attracted many researchers' attention (Wu et al. 2005; Silvana 2004; Elremaily and Azizinamini 2001). In the field of ground engineering, flange joints are most widely used and become the focus of related research fields (Mirza and Uy 2010; Shi et al. 2007). In the field of underground engineering, the most commonly used joints in coal mines are flange joints and casing joints (Fig. 2). Wang et al. (2017) has studied the mechanical properties of quantitative yielding joint of confined concrete arch. Li et al. (2018) has studied the mechanical properties of confined concrete casing joints. However, there's no comparative analysis of the most commonly used types of joints at present, and the joint design of confined concrete arch lacks rational design reference.

\section{Analytical objects}

\subsection{Flange joint and failure modes}

Flange joints consist of flange plates welded at each end of the arch sections and high-strength bolts connecting these flange plates. Figure 3 shows the flange joint structural parameters used in Liangjia Coal Mine. $D$ is the diameter

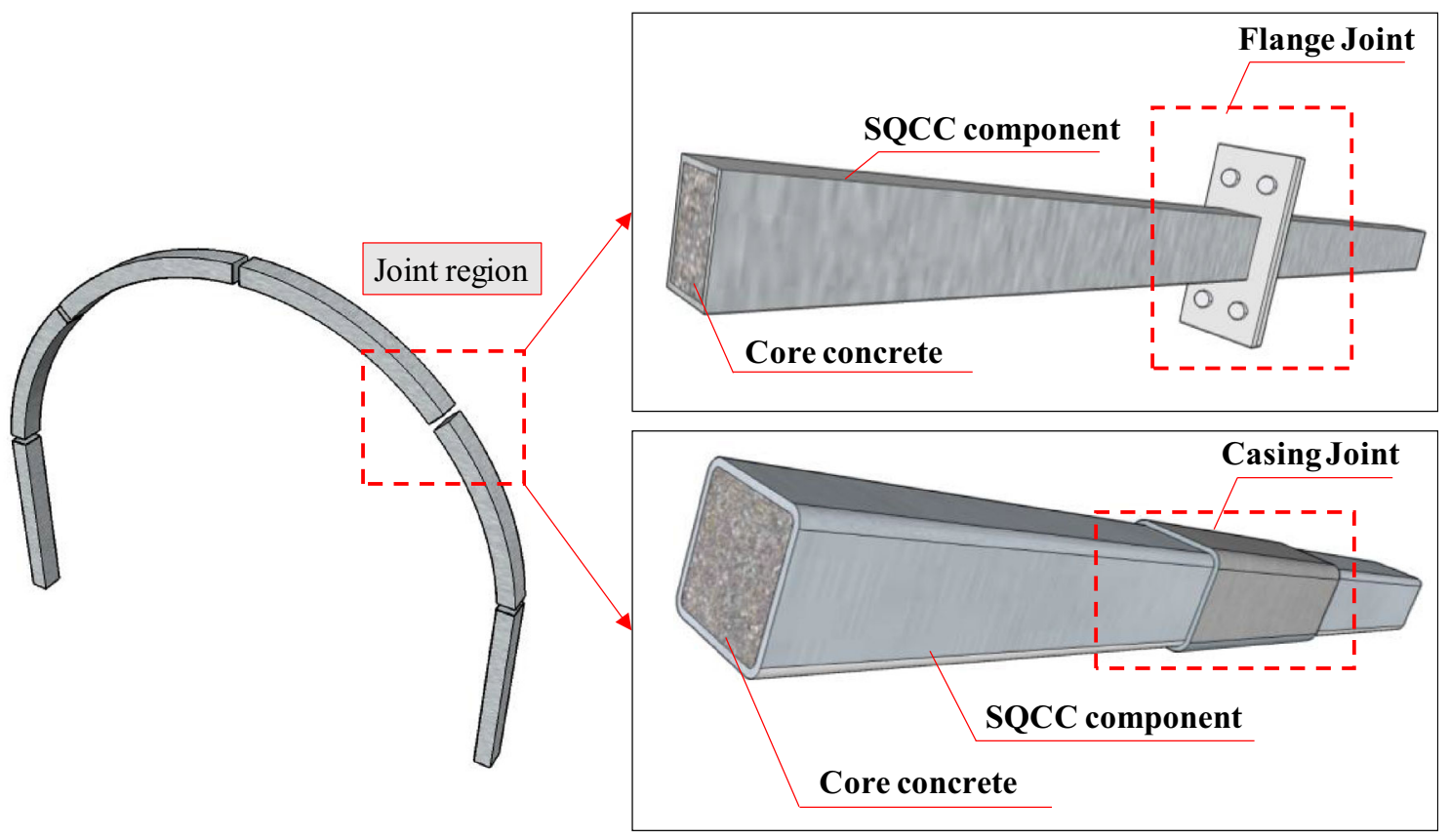

Fig. 2 Flange joint and casing joint 

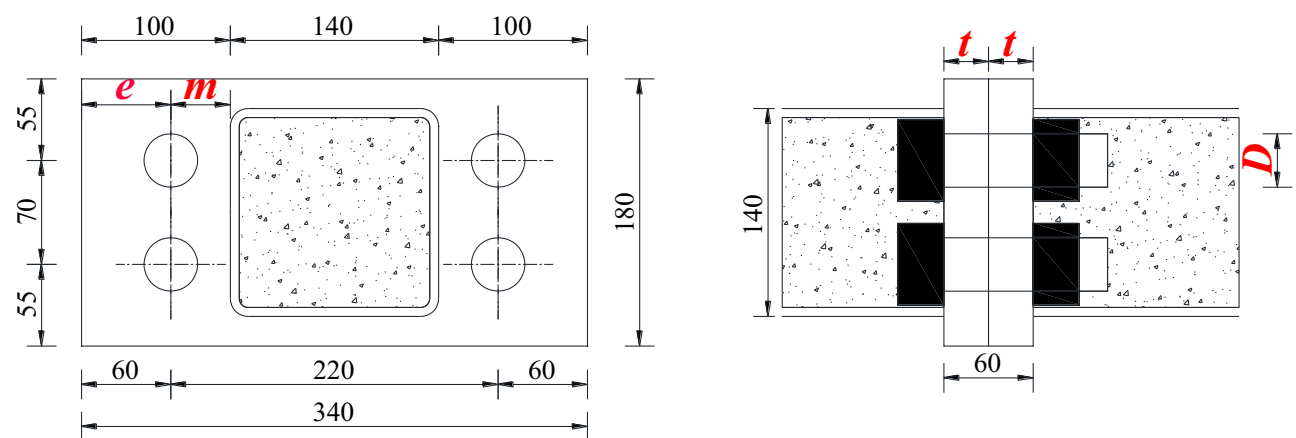

Fig. 3 Structural figure of flange joint

of high-strength bolts and $t$ is the thickness of flange plates while $e$ and $m$ define the location of bolts.

When bending force is loaded on the flange joint, the bolts on the tension side bear tension, while the bolts on the compression side bear compression, and the flange plates bear bending moment. When the tension of the bolt reaches the tensile yield strength or the flange plate reaches bending yield strength, the plastic hinge appears in one or more locations, then the flange joint enters the overall yield state.

Figure 4 shows three main yielding modes of flange joints, each mode represents a specific plastic hinge position. $Q$ is the prying force produced by flange contact. Figure 4a shows Mode 1 that the plastic hinge occurs in the flange plate close to the weld seam, which leads to the yield failure of joint. The overall strength of flange joint in Mode 1 is $M_{1}$. Figure $4 \mathrm{~b}$ shows Mode 2 that the bolt on the tension side reaches the tensile yield strength, which leads to the yield of joint, while the overall yield strength of flange joint is $M_{2}$. Figure $4 \mathrm{c}$ shows Mode 3 in which $M_{1}=M_{2}$.

When $M_{1}<M_{2}$, the specimen failure mode is agreed with Mode 1 .

When $M_{1}>M_{2}$, the specimen failure mode is agreed with Mode 2.

When $M_{1}=M_{2}$, the specimen failure mode is agreed with Mode 3.

By comparing the value of $M_{1}$ and $M_{2}$, the location of the initial yielding of the joint can be identified. The failure mode of the joint which can be used as the criterion of the failure mechanism of the flange joint can also be obtained. Taking the smaller value of the joint, the flexural capacity of flange joint can be estimated.

\subsection{Casing joint and failure modes}

Casing joint is two arch sections connected by a hollow steel tube (casing tube). As shown in Fig. 5, $L$ is the length of casing tube and $b$ is the thickness of casing tube wall.
Due to the different structural parameters such as casing wall thickness and casing length, the joints show different mechanical characteristics.

Figure 6 is the main failure modes of casing joints ( $\mathrm{Li}$ et al. 2018). Because of the gap between the casing tube and the confined concrete component, the joint has a certain rotational capacity at the early loading of the bending moment while the arch rotates around the center at angle $\omega_{0}$, which is defined as the critical rotation angle of the casing joint. Then, due to the restriction of the casing tube, the joint obtains a certain rotational stiffness, then it gets the ability to transfer bending moment between two confined concrete sections.

With the increase of the bending moment, the rotation angle of the joint increases gradually until the rotation angle reaches angle $\theta_{y}$, when the first plastic hinge occurs at one cross-section. Then the casing joint enters the yield stage. $\theta_{y}$ is defined as the yield angle of the casing joint. $\mathrm{Li}$ et al. (2018) studied the failure modes of casing joints and indicates that the first yielding cross-section of casing joint mainly occurs at two locations:

(1) The midpoint cross-section of casing tube, as shown in Fig. 6b: $x$;

(2) The cross-section at the edge of contact ends between casing tube and the confined concrete arch, as shown in Fig. 6b: $y$.

$M_{1}$ is defined as the bearing capacity when location $x$ first yields, while $M_{2}$ is defined as the bearing capacity when location $y$ first yields.

When $M_{1}<M_{2}$, the specimen failure mode is agreed with Mode 1.

When $M_{1}>M_{2}$, the specimen failure mode is agreed with Mode 2.

By comparing the value of $M_{1}$ and $M_{2}$, the location of the initial yielding cross-section of the joint can be identified. Taking the smaller value of the joint, the flexural capacity of casing joint can be estimated. Because of the 
Yielding point

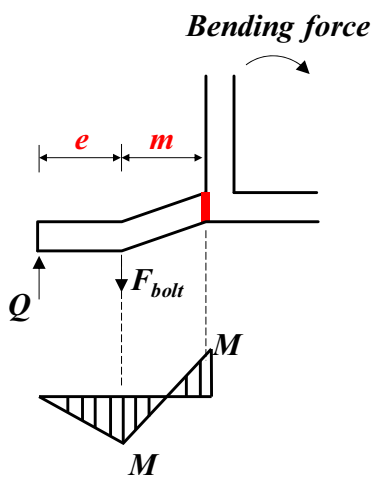

(a) Mode 1

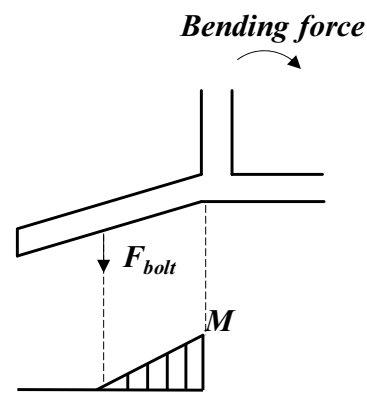

(b) Mode 2

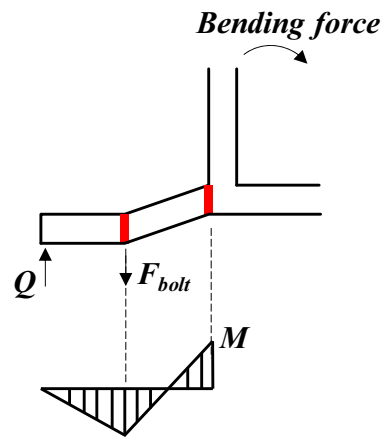

(c) Mode 3

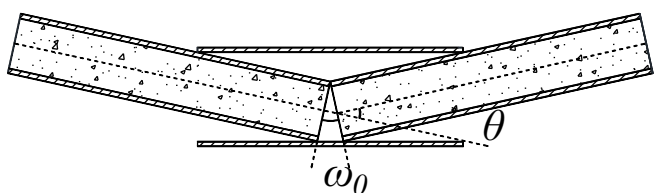

(a) Research object

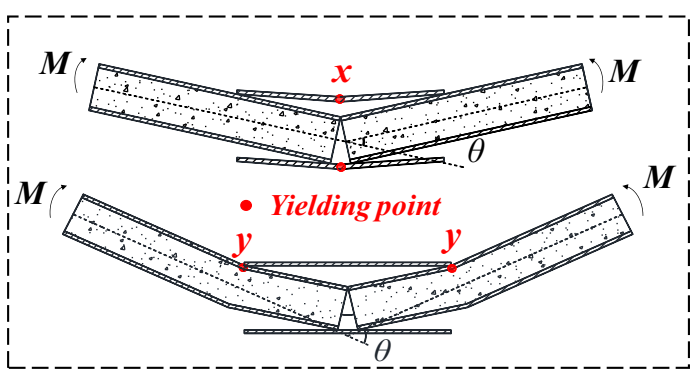

(b) Failure modes of casing joint

Fig. 6 Failure mode of casing joint

different structural parameters of casing joint, at least one of the two weak sections enter the yield state first.

\section{Experimental analysis of two kinds of joint}

\subsection{Experiment overview}

\subsubsection{Laboratory experiment}

Laboratory bending test of joint is carried out by large hydraulic servo system and reaction device. The test is loaded by a vertical hydraulic device and the four-point loading mode is adopted to ensure that the joint area is in a pure bending state. In the test, two strain observation sections were set up, and five displacement meters were arranged longitudinally to record the deformation process and rotation angle of the specimens.

The parameter selection of joint specimens depends on the most widely used casing and flange joints in engineering, as shown in Figs. 4 and 5. The bolt diameter of the flange joint is $36 \mathrm{~mm}$, the flange plate thickness is $40 \mathrm{~mm}$, the casing wall thickness of the casing joint is $12 \mathrm{~mm}$, and

Fig. 4 Failure mode of flange joint
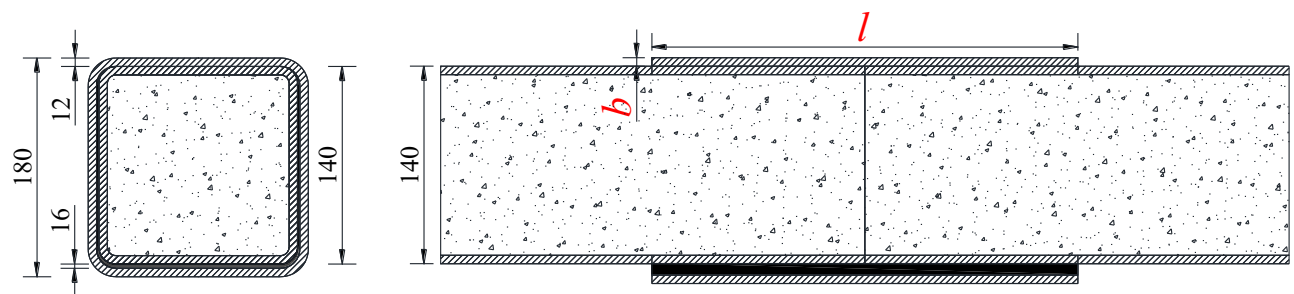

Fig. 5 Structural figure of casing joint 

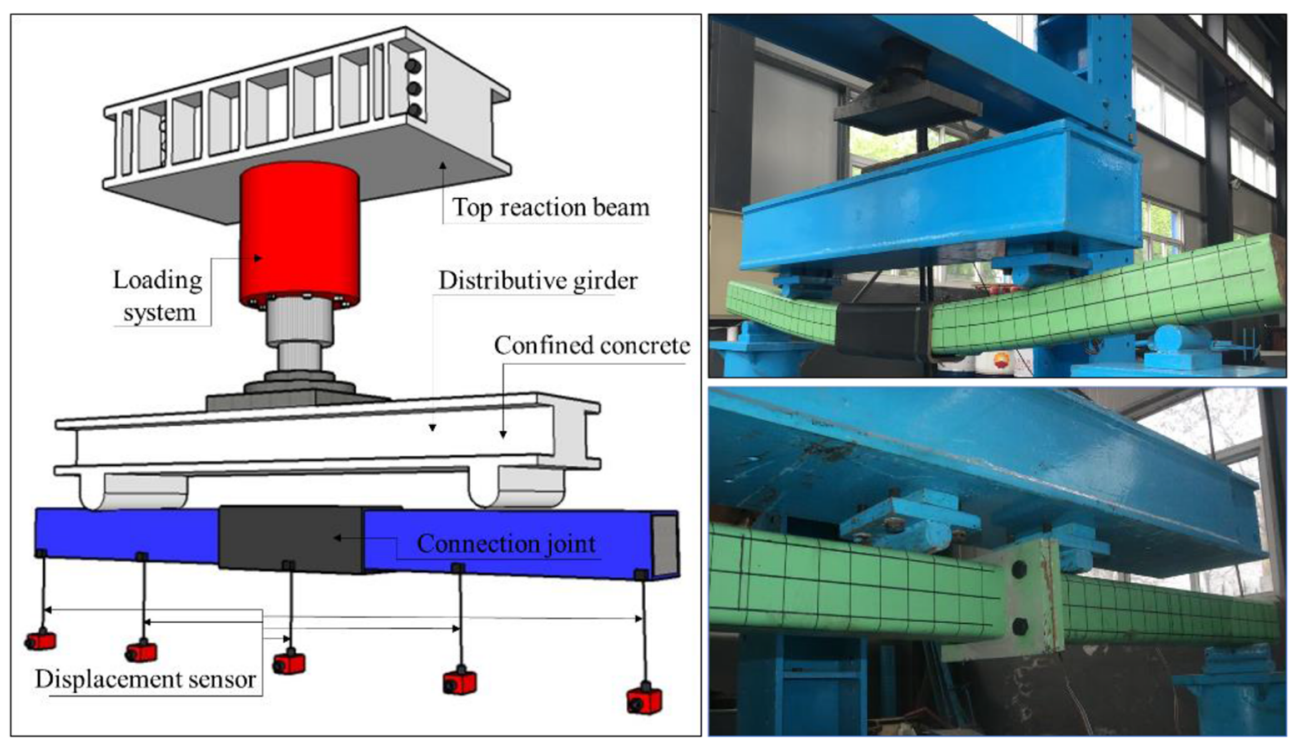

Fig. 7 Pure bending laboratory experiment of different kinds of joint

the casing length is $500 \mathrm{~mm}$. The loading scheme of the specimen is shown in Fig. 7.

\subsubsection{Numerical experiment}

The numerical experiment is carried out based on largescale general finite element software ANSYS. Solid45 unit is adopted for steel, Solid65 unit is adopted for concrete and CONTAL173 unit is adopted for contact between steel tube and concrete, between bolts and flange plates, and between casing joints and arch sections. One end of the specimen is restrained in three dimensions while the rotation is free, and the other end is not restrained longitudinally, which means the specimen boundary condition conforms to the simply supported beam constraint. Two concentrating forces are applied on the specimen symmetrically, so the specimens are loaded by four-point bending, which is consistent with the laboratory test (Fig. 8).
The constitutive relation curve of steel can be referred to formula (1). The stress-strain curve was established by using ANSYS multi-linear dynamic hardening model KINH.

$\begin{array}{lll}\text { Elastic stage: } & \sigma=\varepsilon E_{s} & 0 \leq \varepsilon \leq \varepsilon_{y} \\ \text { Yielding stage: } & \sigma=\varepsilon \frac{E_{\mathrm{s}}}{20}-\frac{\sigma_{y}}{20}+\sigma_{y} & \varepsilon_{y} \leq \varepsilon \leq \varepsilon_{u} \\ \text { Plastic stage: } & \sigma=\sigma_{u} & \varepsilon \geq \varepsilon_{u}\end{array}$

The plastic properties of concrete in confined concrete are quite different from ordinary concrete due to the restraint of steel tube. Han et al. (2007) fully considered the restraint effect of steel tube on concrete. After a lot of experiments and finite element research, the stress-strain formula of core concrete suitable for concrete filled steel tube structure was proposed. The stress-strain curve of concrete was constructed using KINH model. Material constitutive model refers to relevant research content (Han et al. 2007; Fan 2013; Javed et al. 2017).
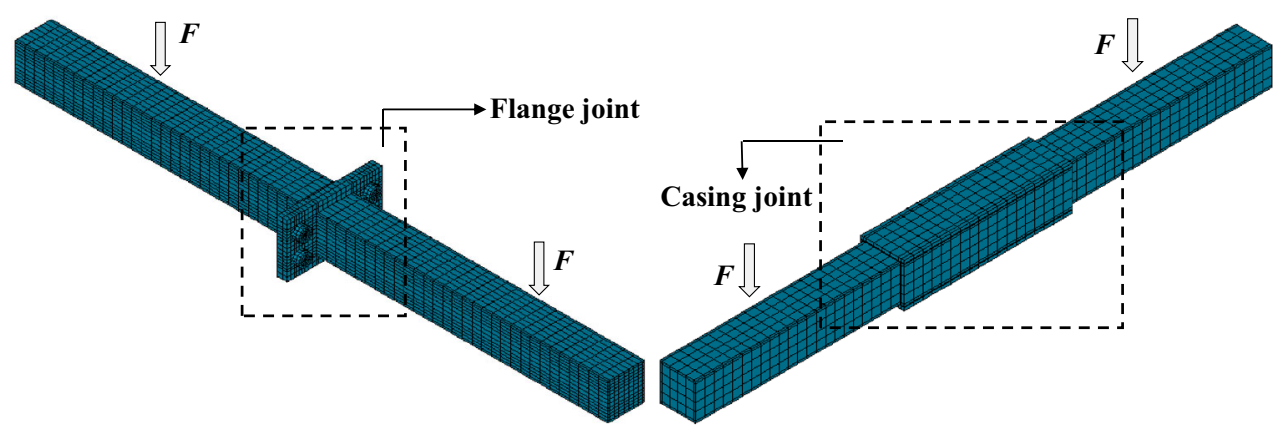

Fig. 8 Numerical model of joints 


\subsection{Experiment process}

During the loading process, the joint specimens show obvious bending deformation. The specimens are in the state of elastic deformation at the initial stage of loading, and there is no obvious deformation and failure characteristics of the specimens. With the increase of load, the specimens enter the yield stage, the rotation angle increases rapidly, and the vertical load tends to be stable gradually.

In the pure bending test of flange joints, the weld strength of flange plate is low due to the length limitation of the weld between confined concrete components and joints. Therefore, at the beginning of the test, the damage of flange joints is caused by the tearing of the weld. In order to enhance the welding strength, two stiffening rib plates were added on both compression and tension sides of the flange plate. The failure mode of the flange joint then changed obviously. The bolts on the tension side appeared obvious tension deformation. Up to the end of the test, bolts at the tension side break, and bending deformation of the specimens is obvious.

Casing joint shows simple structure and clear force transfer mechanism in the test process, which avoids the complex deformation mechanism as flange joint. At the beginning of the test, the load of the specimen is stable, and the deformation is small. Then the confined concrete arch section tends to show obvious deformation. The sound of concrete cracking can be heard during this period. By the end of the test, local buckling occurs and the paint peeling off at the compression side. The ultimate load of the specimen reaches 2.85 times of that of the flange joint, and it shows strong ductility and good deformation ability (Fig. 9).

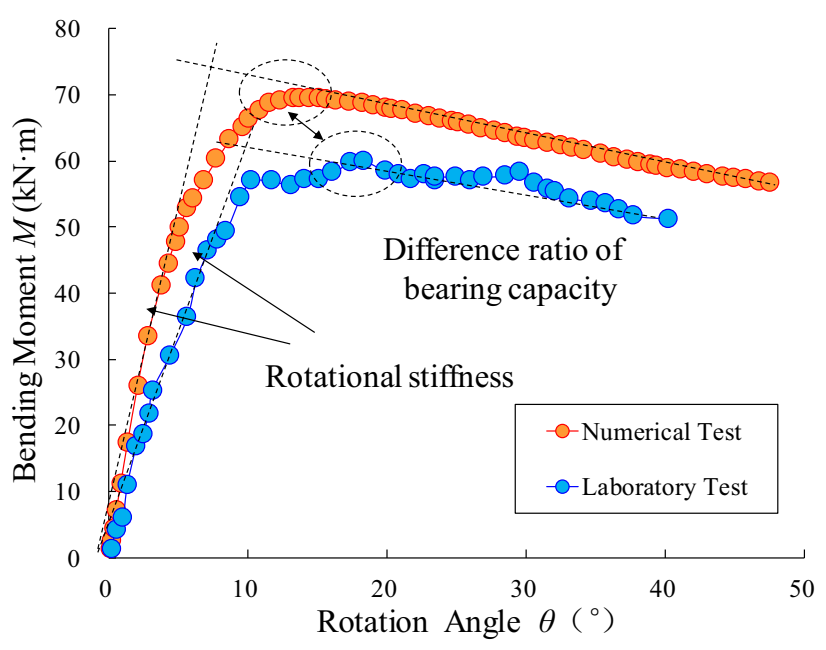

Fig. 10 Comparison of laboratory result and numerical result (based on flange joint)

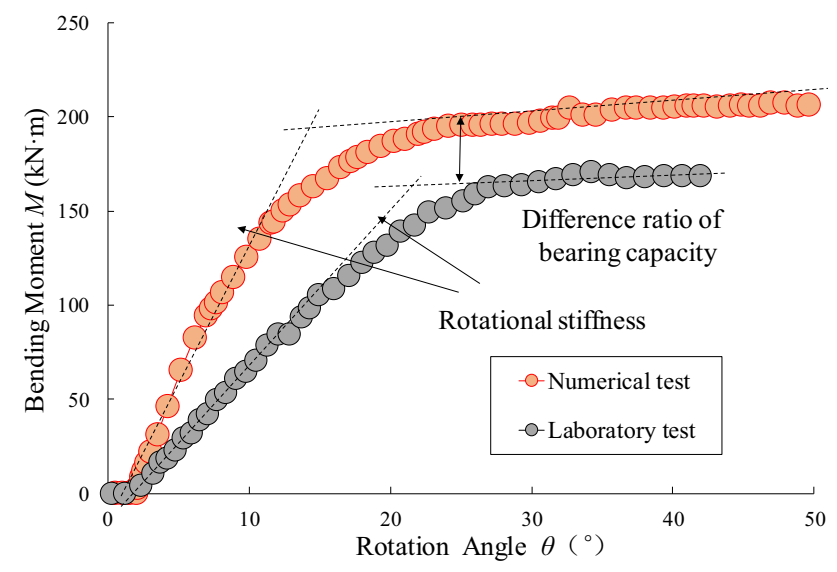

Fig. 11 Comparison of laboratory result and numerical result (based on casing joint)
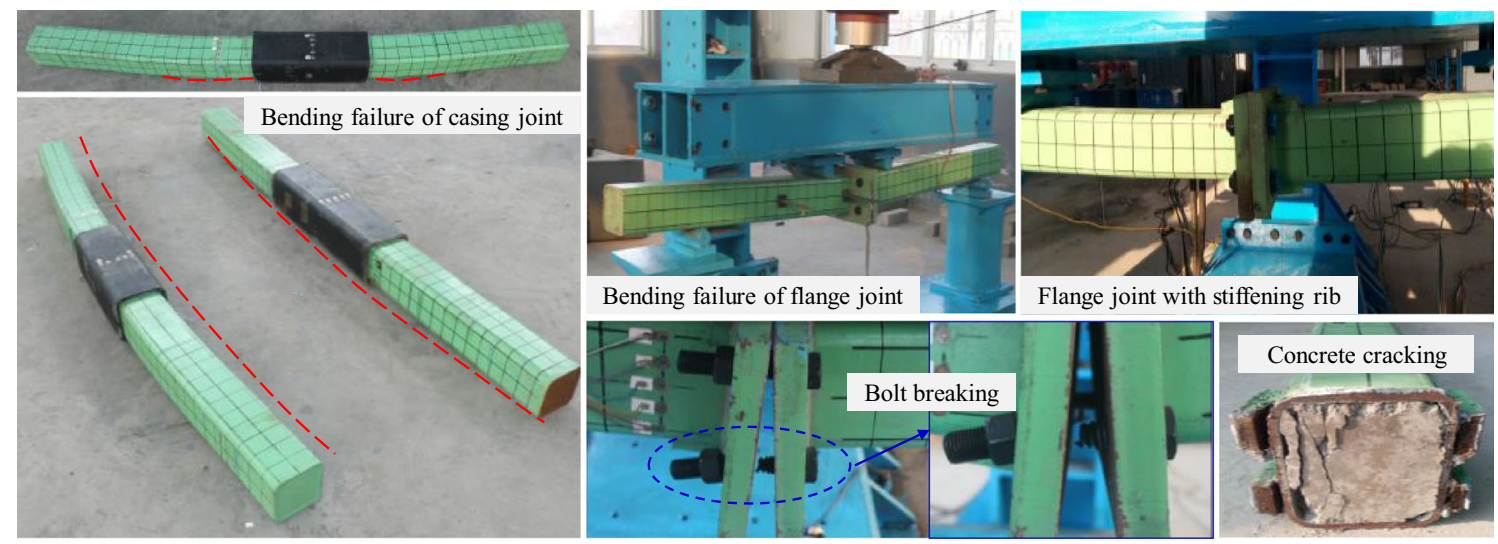

Fig. 9 Test specimen failure deformation 


\subsection{Results and discussion}

\subsubsection{Comparison of laboratory and numerical experiments}

Figures 10 and 11 are comparisons of $M-\theta$ curves of laboratory and numerical tests for flange and casing joints. The curves of both specimens show three stages of elastic stage, yield stage and plastic stage.

Based on the test results, the difference of bearing capacity of flange joints in laboratory test and numerical test is $14.76 \%$, and that of casing joints is $18.83 \%$. The results show that the numerical test is consistent with the laboratory test results, and the numerical test scheme meets certain accuracy requirements. The results of numerical test are slightly higher than those of laboratory test, because the numerical test satisfies the ideal loading conditions better.

\subsubsection{Comparison of different kinds of joints}

Figures 12 and 13 show the comparison of $M-\theta$ curves between flange joints and casing joints. Based on the test results:

(1) At the beginning of loading on casing joint, there is an obvious critical turning angle. In this stage, the casing joint should be assumed as an articulated joint, and the arch sections connected by casing joint will show a certain free deformation capacity under bending moment.

(2) The strength of flange joints develops rapidly in the initial stage, and the bearing capacity of flange joints decreases slightly after yielding, then the load tends to be stable and the flange joints have relatively good later bearing capacity.

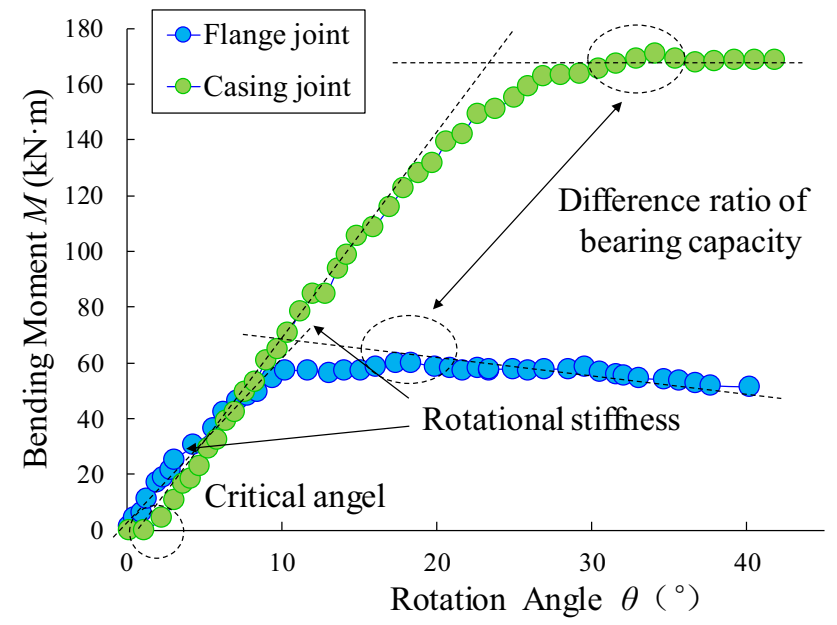

Fig. 12 Comparison of two kinds of joints in laboratory test

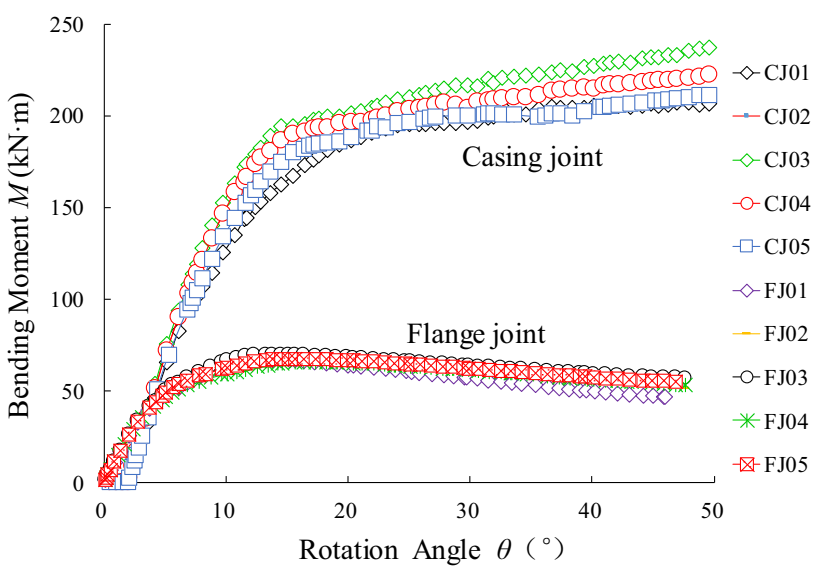

Fig. 13 Comparison of two kinds of joints in numerical test

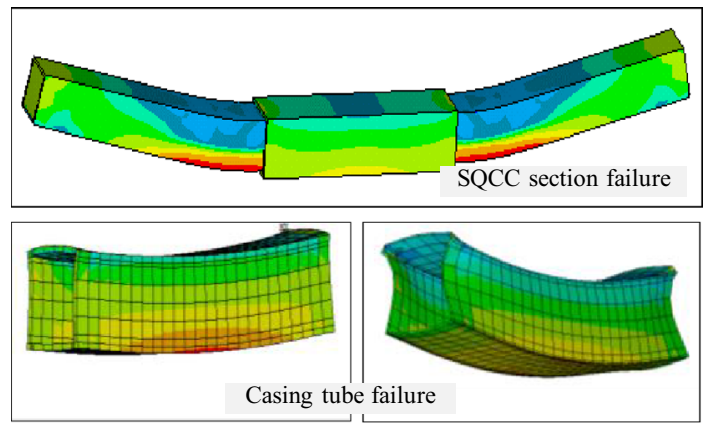

(a) Casing joint deformation

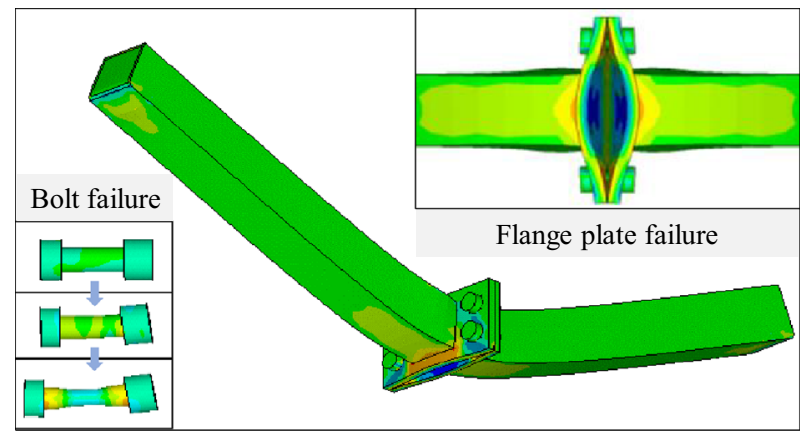

(b) Flange joint deformation

Fig. 14 Numerical result of joint

(3) The stiffness of casing joints is slightly greater than that of flange joints. The ultimate strength of casing joints is 2.85 times of that of flange joints. The force transmission mechanism is clear, and the load is uniform. The casing joints have good ductility and ultimate deformation capacity.

From the deformation and failure modes of the specimens in the numerical experiments (Fig. 14), it can be seen 
Table 1 Parameters of flange joints

\begin{tabular}{llll}
\hline $\begin{array}{l}\text { Specimen } \\
\text { name }\end{array}$ & $\begin{array}{l}\text { Arch } \\
\text { component } \\
\text { type }\end{array}$ & $\begin{array}{l}\text { Cross section } \\
\text { diameter of bolt } \\
(\mathrm{mm})\end{array}$ & $\begin{array}{l}\text { Thickness of } \\
\text { flange plate } \\
(\mathrm{mm})\end{array}$ \\
\hline FJ01 & SQCC 140-6 & 24 & 40 \\
FJ02 & & 30 & 40 \\
FJ03 & 36 & 40 \\
FJ04 & 36 & 20 \\
FJ05 & 36 & 30 \\
\hline
\end{tabular}

140 in SQCC 140-6 means the height of square confined concrete section and 6 means the thickness of the square tube

that the failure modes of casing joints and flange joints are consistent with the analysis of failure modes in Sect. 2.

(1) When the thickness of the casing tube is small, the bending strength of the casing tube is relatively low, it is easy to buckle, and the overall strength of the joint is low. When the thickness of the casing is larger, the strength of the joints increases significantly, and the overall strength is determined by the strength of the confined concrete components. Then the stress at the end of confined concrete component increases while the local bending is more obvious.

(2) When the bolt diameter is larger and the flange plate thickness is smaller, the flange plate bends along the transverse direction obviously. However, when the bolt diameter is smaller and the flange plate thickness is larger, the bolts on the tension side are obviously pulled. Because the deformation mechanism of flange joints is complex, the release of deformation energy of flange joint specimen is mainly concentrated in the joint region, and the bending of confined concrete components is relatively small.

\section{Parameter influence mechanism of different joints}

\subsection{Flange joint}

As mentioned above, the bending strength and stiffness of flange joints are mainly affected by flange thickness $t$ and bolt diameter $D$. Based on engineering practice, five typical flange joints are selected as the research objects. The main parameters are listed in Table 1.

Figures 15 and 16 show the comparison of $M-\theta$ curves of flange joints with different design parameters. It can be indicated from the test results:

(1) The influence of bolt diameter on the initial stiffness and yield strength of the joint is not obvious, which indicates that the elastic stage is controlled by the thickness of flange plate. After the bending moment in flange plate reaches the yielding strength, the later

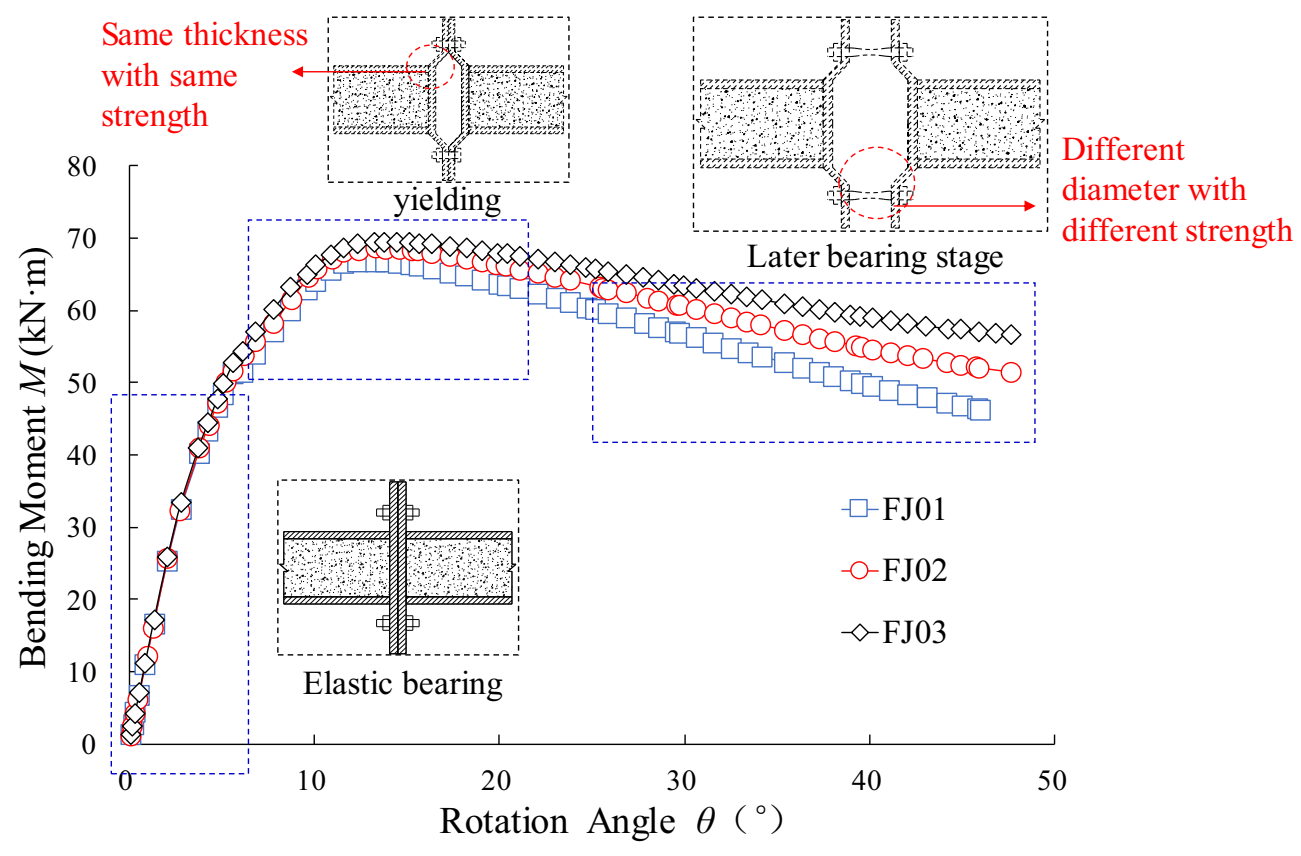

Fig. $15 M-\theta$ curve of flange joints with different cross section diameter of bolt 


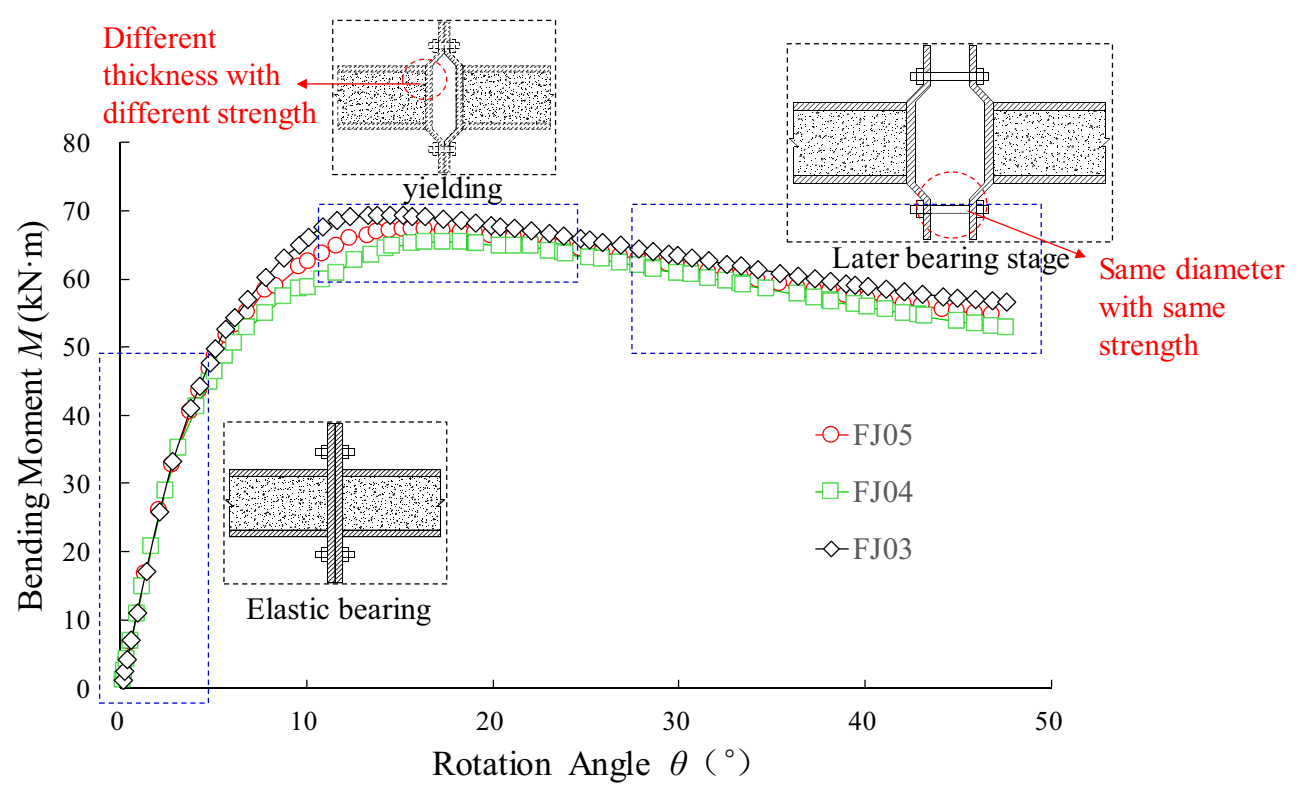

Fig. $16 M-\theta$ curve of flange joints with different thickness of flange plate

bearing capacity of the joint is mainly affected by the tensile strength of bolts. As the diameter of bolts getting bigger, the ultimate strength of flange joint gets higher. That means the failure mode of selected flange joints is consistent with Mode 1.

(2) The thickness of flange plate has obvious influence on the yielding strength of joints, but has little influence on the stiffness and later bearing capacity of joints. This conclusion is consistent with Fig. 15. The strength of flange joints is mainly affected by the bending strength of flange plate, and the bending yield of flange plates on the tension side of joints leads to the overall yield of joints. Later bearing capacity of flange joints is mainly affected by bolt tensile strength. As indicated in Fig. 16, with the same thickness of bolt, the curves in plastic stage are basically in coincidence with each other.

Table 2 Parameters of casing joint

\begin{tabular}{lllll}
\hline $\begin{array}{l}\text { Specimen } \\
\text { name }\end{array}$ & $\begin{array}{l}\text { Arch } \\
\text { component } \\
\text { type }\end{array}$ & $\begin{array}{l}\text { Casing } \\
\text { tube height } \\
(\mathrm{mm})\end{array}$ & $\begin{array}{l}\text { Casing } \\
\text { tube length } \\
(\mathrm{mm})\end{array}$ & $\begin{array}{l}\text { Thickness of } \\
\text { casing tube } \\
(\mathrm{mm})\end{array}$ \\
\hline CJ01 & SQCC & 180 & 500 & 12 \\
CJ02 & $140-6$ & 180 & 700 & 12 \\
CJ03 & & 180 & 900 & 12 \\
CJ04 & & 172 & 900 & 8 \\
CJ05 & & 164 & 900 & 4 \\
\hline
\end{tabular}

\subsection{Casing joint}

As mentioned above, the bending strength and stiffness of casing joints are mainly affected by the thickness of casing wall $b$ and the length of casing $l$. Based on engineering practice, five typical casing joints are selected as the research objects. The main parameters are selected as shown in Table 2.

Figures 17 and 18 show the comparison of $M-\theta$ curves of casing joints with different design parameters. It can be indicated from the test results:

(1) The length of casing tube has obvious influence on the mechanical properties of joints. It can be concluded that the yielding strength of the selected casing joint is controlled by the bending strength of SQCC components based on the contrast of $M-\theta$ curves. The longer the casing length is, the larger the reinforcement area of confined concrete members is, and the more obvious the reinforcement effect is. There are obvious changes in elastic stage, the yielding stage and the plastic stage because the casing tube length also affects the strength of casing tube. The initial stiffness of members increases with the increase of the casing length, and the yielding strength and ultimate strength of casing joints increase significantly.

(2) Casing wall thickness has obvious influence on the mechanical properties of joints. This conclusion is consistent with Fig. 17. With the increase of casing wall thickness, the influence of thickness on initial stiffness and yielding strength is relatively small. However, the ultimate strength of the joints increases 


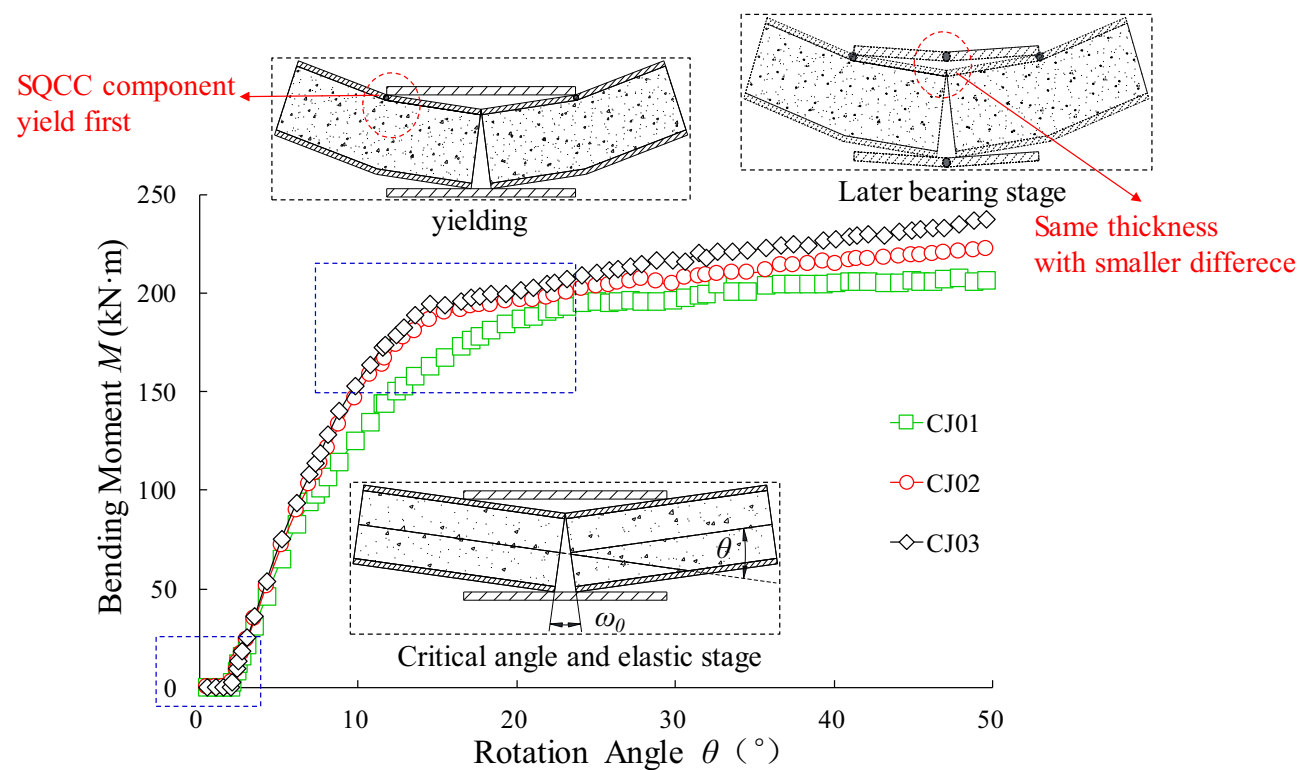

Fig. $17 M-\theta$ curve of casing joint with different casing tube length

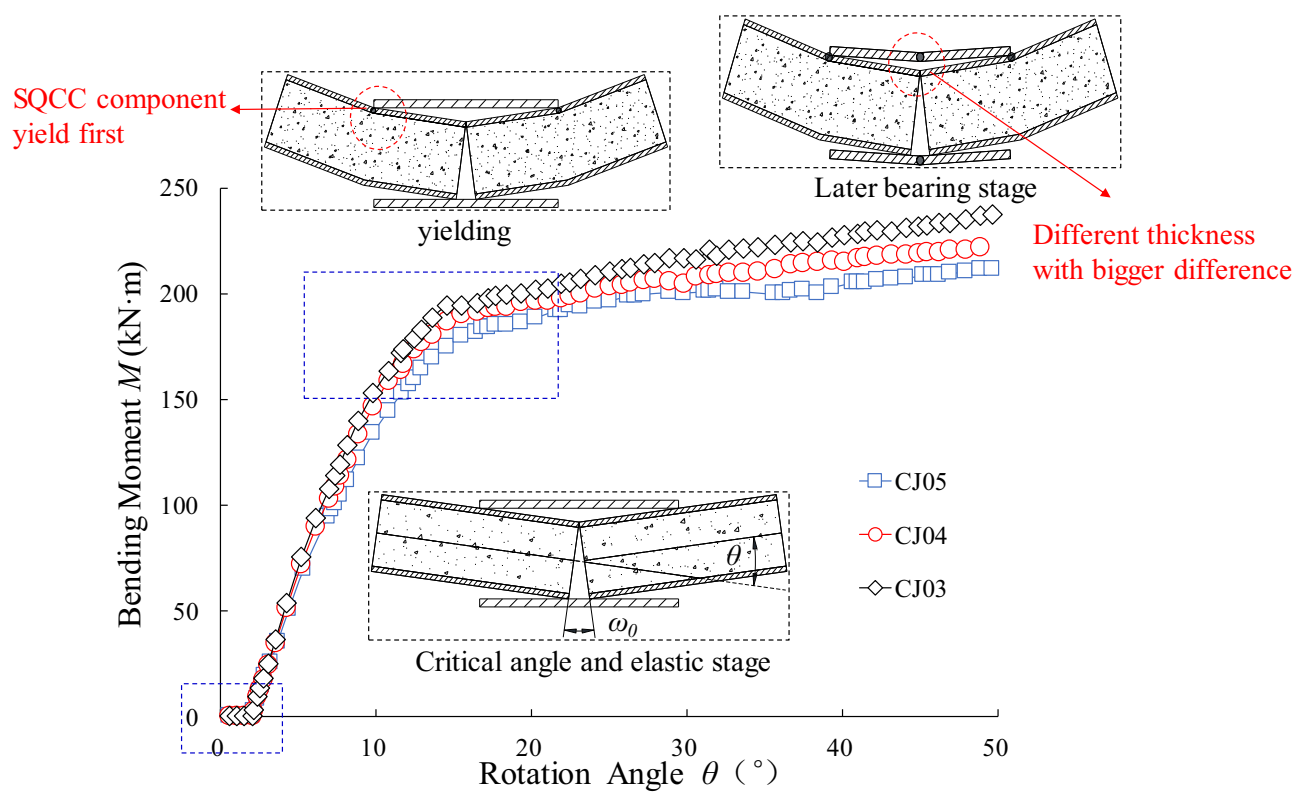

Fig. $18 M-\theta$ curve of casing joint with different casing tube thickness

obviously with the increase of casing wall thickness, which indicates that the change of casing wall thickness does not affect the load transfer mechanism and failure mode of the specimens. The failure process of the selected casing joints complies with Mode 2.

\subsection{Design advice}

(1) In the process of SQCC arch joints design, the failure modes of the joints should be predicted according to the designed structural parameters of the joints. The design strength of joints could be estimated and compared with jointless SQCC component. The strength of joints should be greater than that of jointless components to ensure the full play of the bearing capacity of arches.

(2) Casing joints are simple in construction, and no additional welding operation is needed. The bearing mechanism of casing joints is clear and rational, and the reinforcement effect of casing tubes on confined concrete arch components is obvious. Meanwhile, 

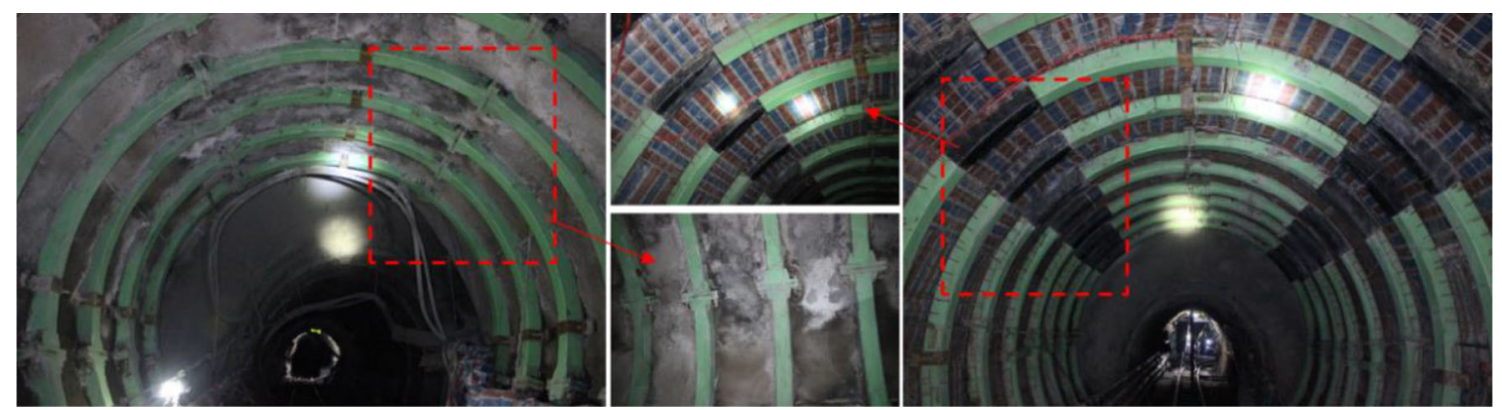

Fig. 19 Field application of two kinds of joints

the construction of casing joints is convenient, and the production of casing joints is simple, which greatly reduces the construction difficulty and economic costs. It should be taken as the optimal joint form of confined concrete arch.

(3) The welded flange joints on confined concrete arch are subject to the limitation of weld length, and the weld strength of flange plates is easy to become a weak link in the process of bearing. The tearing of weld seams will lead to brittle failure of confined concrete arch, which should be avoided in engineering. After adding stiffeners to the flange plate, the weld strength of flange plate increases obviously, which can avoid brittle failure of joints and enhance ductility of joints.

\section{Field application}

Based on the above conclusions, the confined concrete arch is applied to the upper track section of No. 46 mining area in Liangjia Coal Mine (Wang et al. 2017). Flange joints and casing joints are used as the joints of confined concrete arch respectively. Backfilling is carried out between arch and surrounding rock to ensure the surrounding rock load is fully transmitted to arch, in order to avoid stress concentration, as shown in Fig. 19. Field monitoring results show that the confined concrete support achieves good support effect. The stress of each measuring point is basically stable after 93 days of monitoring. Compared with roadway supported by U-type arch, the deformation is only $22.4 \%$ under the support of confined concrete arch, and there is no obvious failure in confined concrete arch, which proves the effectiveness of surrounding rock control of confined concrete support system. The construction efficiency has been greatly improved by using casing joints for on-site confined concrete arch. The installation of flange joints shows poor quality due to the inconvenience of construction. Casing joint is a kind of joint with higher engineering applicability because of its higher strength, higher stiffness and convenient construction.

\section{Conclusion}

(1) The transmission mechanism of casing joint is clear, and the strengthening effect of casing on confined concrete arch is obvious. On the other hand, the casing joints are simple to produce and easy to construct, which greatly reduces the construction difficulty and economic cost. It should be used as the optimal joint form for confined concrete arch where possible.

(2) At the initial loading period of casing joint, there is a clear critical rotation angle. In this stage, the casing joints should be assumed as articulated joints, and the arch has a certain free deformation capacity. The stiffness of casing joints is greater than that of flange joints, and the ultimate strength of casing joints is 2.85 times of that of flange joints. Both the two types of joints have good ductility and ultimate deformation capacity.

(3) The thickness of flange plate and bolt diameter have significant effects on the mechanical properties of flange joints, while the length of casing tube and the thickness of casing wall have significant effects on the mechanical properties of casing joints. In the process of joints design, the failure modes of joints should be predicted according to the structural parameters, and the parameter that dominate the bearing strength should be defined. Then, according to the design strength of arch, the parameters should be changed to meet the design requirements of joints.

Acknowledgements This study was funded by The Natural Science Foundation of Shandong Province, China (Nos. ZR2017QEE013, 2017GGX30101, 2018GGX109001), The Young Scholars Program of Shandong University (2018WLJH76), The Research Fund of The State Key Laboratory of Coal Resources and safe Mining, CUMT (SKLCRSM18KF012). 
Open Access This article is distributed under the terms of the Creative Commons Attribution 4.0 International License (http://crea tivecommons.org/licenses/by/4.0/), which permits unrestricted use, distribution, and reproduction in any medium, provided you give appropriate credit to the original author(s) and the source, provide a link to the Creative Commons license, and indicate if changes were made.

\section{References}

Elremaily A, Azizinamini A (2001) Experimental behavior of steel beam to CFT column connections. Constr. Steel. Res 57:1099-1119

Fan Z (2013) Study on the FE model updating and structural damage detection for long-span cable-stayed bridges. Dissertation, Dalian University of Technology

Gao YF, Liu KM, Feng SW et al (2015) Early strength concrete experiment and applied research of early strength concrete-filled steel tubular supports in extremely soft rock roadways. Journal of Mining \& Safety Engineering 32:537-543

Han LH, Yao GH, Tao Z (2007) Performance of concrete-filled thinwalled steel tubes under pure torsion. Thin. Wall. Struct. 45:24-36. https://doi.org/10.1016/j.tws.2007.01.008

He MC, Jing HH, Sun XM (2002) Soft rock engineering mechanics. Science Press, Beijing

Javed MF, Sulong NHR, Memon SA, Rehman SKU, Khan NB (2017) FE modelling of the flexural behaviour of square and rectangular steel tubes filled with normal and high strength concrete. Thin. Wall. Struct. 119:470-481. https://doi.org/10.1016/j.tws.2017. 06.025
Li X (2012) Steel tube compression confined concrete strength and the roadway ring enhanced support theory. Dissertation, China University of Mining and Technology

Li SC, Lu W, Wang Q et al (2018) Study on failure mechanism and mechanical properties of casing joints of square steel confined concrete arch. Eng Fail Anal 92:539-552. https://doi.org/10. 1016/j.engfailanal.2018.05.011

Meng D (2013) Research on support theory and support technology of concrete-filled steel tubular support of soft rock roadway in Yang Zhuang Coal Mine. Dissertation, China University of Mining and Technology

Mirza O, Uy B (2010) Experimental studies of behaviour of composite beam-column flush end plate connections subjected to seismic loading. Cheminform 27(44):1307-1313. https://doi. org/10.1002/chin.199644033

Shi G, Shi YJ, Wang YQ (2007) Behaviour of end-plate moment connections under earthquake loading. Eng Struct 29:703-716. https://doi.org/10.1016/j.engstruct.2006.06.016

Silvana DN (2004) An experimental study of connections between 1-beams and concrete filled steel tubular columns. Steel. Compos. Struct 4:303-315

Wang Q, Jiang B, Li SC et al (2016) Experimental studies on the mechanical properties and deformation \& failure mechanism of U-type confined concrete arch centering. Tunn. Undergr. Sp. Technol 51:20-29. https://doi.org/10.1016/j.tust.2015.10.010

Wang Q, Jiang B, Pan R et al (2017) Failure mechanism of surrounding rock with high stress and confined concrete support system. Int J Rock Mech Min Sci 102:89-100. https://doi.org/10. 1016/j.ijrmms.2018.01.020

Wu L, Chung L, Tsai S (2005) Seismic behavior of bolted beam to column connection for concrete filled steel tube. J Constr Steel Res 61:1387-1410 